\title{
Addressing the adverse consequences of disability on health status in rural settings
}

Sir, Disability refers to a combination of impairments, constraints in performing work, and restrictions in involvement, which often results due to the close 
interplay between an individual's health status and their environment (intrinsic/extrinsic/social). ${ }^{[1]}$ People with disabilities are one of the most marginalized sections across the world, predominantly because more than by their bodies, they are disabled by the community. ${ }^{[2]}$ In fact, excess of 1 billion people have one or another form of disability, whereas close to 110-190 million adults have major limitations in performing their routine activities ${ }^{[3]}$ In addition, these estimates are supposed to rise further owing to the increase in life expectancy and acquisition of lifestyle diseases. ${ }^{[1,3]}$

It is very important to acknowledge that people with disabilities have very high unmet needs, as most of the health promotion and other preventive package of services are never targeted toward them. ${ }^{[1]}$ In fact, people with disability from different age groups have to encounter varied forms of health services deprivations (viz., adolescents with disability are deprived of sexual and reproductive health needs, adults with disability are deprived of routine screening measures or regular health interventions, etc.). ${ }^{[3]}$ Further, many secondary conditions (such as bed sores, and infections.), comorbid conditions (such as onset of diabetes in schizophrenia patients), age-related conditions, adoption of high-risk behaviors (viz., substance abuse, poor lifestyle measures), and higher rates of premature deaths have been reported among people with disabilities. ${ }^{[3]}$ All these conditions are both foreseeable and therefore preventable, provided the stakeholders are willing to make a difference. ${ }^{[1,3,4]}$

Moreover, especially in developing nations and rural settings, people with disability are exposed to different kinds of barriers, which in combination prevent them from availing health care services. ${ }^{[2]}$ These include affordability, transport constraints, nonexistence of the desired services in some geographical regions, presence of isolated services in a health establishment (not complete package - ideal case), physical constraints (viz., uneven access to health centers, inability to use available medical equipments, no signage boards, questionable restroom facilities, no access to parking slots, etc.), and untrained or ill-sensitized health professionals to meet the needs of people with disabilities. ${ }^{[1,2,5]}$

To significantly improve the health outcomes among people with disability, there is a great need to address the existing shortcomings to ensure that health services are quality assured, affordable, and delivered within the existing framework of resources. ${ }^{[1-3]}$ Nevertheless, as the health needs of people with disability are not limited to health sector alone, cooperation is required from all the stakeholders. [1,5] The primary intervention is to assess the existing policies and services so that deficient areas can be identified and corrective strategies can be planned to expand the range of benefits to all those who are in need. ${ }^{[3]}$ In addition, measures to facilitate access to health care services by neutralizing physical barriers, sensitization of the health professionals about the special needs of the people with disability, their motivation for self-care, encourage community-based rehabilitation in heterogeneous settings, and conduct large-scale research work pertaining to the needs, barriers, and health outcomes for people with disabilities can also provide enough support. ${ }^{[1-5]}$ However, none of the above measures can provide sustainable results, unless continued financial support is extended at all levels. ${ }^{[1,3]}$

To conclude, acknowledging the global magnitude of disability, extensive resource constraints in rural settings, and serious violation of human rights, the need of the hour is to ensure that national governments, voluntary health agencies, health sector, and people with disability along with their families should work in a coordinated manner to minimize the adverse outcome of the disability.

\section{Financial support and sponsorship}

Nil.

\section{Conflicts of interest}

There are no conflicts of interest.

Saurabh RamBihariLal Shrivastava, Prateek Saurabh Shrivastava, Jegadeesh Ramasamy

Department of Community Medicine, Shri Sathya Sai Medical College and Research Institute, Kancheepuram, Tamil Nadu, India

Address for correspondence: Dr. Saurabh RamBihariLal Shrivastava Department of Community Medicine, Shri Sathya Sai Medical College and Research Institute, $3^{\text {rd }}$ Floor, Ammapettai

Village, Thiruporur, Guduvancherry Main Road, Sembakkam Post, Kancheepuram - 603 108, Tamil Nadu, India. E-mail: drshrishri2008@gmail.com

\section{References}

1. World Health Organization. World Report on Disability. Geneva: WHO Press; 2011.

2. Shrivastava SR, Shrivastava PS, Ramasamy J. Holistic measures for the welfare of the differently-abled children. Arch Med Health Sci 2014;2:114-5. 
3. World Health Organization. Disability and Health - Fact Sheet No. 352; 2015. Available from: http://www.who.int/mediacentre/factsheets/ fs352/en/. [Last accessed on 2015 Dec 05].

4. Soltani S, Khosravi B, Salehiniya H. Prevalence of Disability in Iran. Iran J Public Health 2015;44:1436-7.

5. Shrivastava S, Shrivastava P, Ramasamy J. Exploring the scope of community-based rehabilitation in ensuring the holistic development of differently-abled people. Afr Health Sci 2015;15:278-80.

This is an open access article distributed under the terms of the Creative Commons Attribution-NonCommercial-ShareAlike 3.0 License, which allows others to remix, tweak, and build upon the work non-commercially, as long as the author is credited and the new creations are licensed under the identical terms.

\begin{tabular}{|l|l|}
\hline \multicolumn{2}{|c|}{ Access this article online } \\
\hline Quick Response Code: & Website: \\
\hline & www.ruralneuropractice.com \\
\hline & \\
\hline
\end{tabular}

How to cite this article: Shrivastava SR, Shrivastava PS, Ramasamy J. Addressing the adverse consequences of disability on health status in rural settings. J Neurosci Rural Pract 2016;7:319-21. 